\title{
Application of Incentive Theory in Hospitals' Human Resource Management
}

\author{
Xiuxia Liu* \\ Community Health Service Center of Fu'an Street, Jiaozhou 266300, Shandong Province, China \\ *Corresponding author: Xiuxia Liu, songsong0845@sina.com
}

\begin{abstract}
In recent years, the modern medical system has achieved deepening reforms, and the management systems of domestic hospitals have changed accordingly, which has improved the level of modern management to a certain extent. However, the development of hospitals is easily affected by many factors, which gradually highlights the problems of internal human resource management. This is not conducive for improvement in terms of the enthusiasm and initiative of internal employees in addition to restricting the quality of medical services. Based on this, in hope to provide assistance, this article uses incentive theory as the main research object and focuses on its specific application in hospitals' human resource management.
\end{abstract}

Keywords: Incentive theory; Hospital; Human resource management; Application

Publication date: August 2021; Online publication: August 30, 2021

\section{Introduction}

Human resource management plays an important role in various management work of hospitals where the quality of human resource management would have an impact on the gains and losses of hospital talents, the enhancement of market competitiveness, and it would also affect the health of the people. The main purpose of optimizing human resource management is to stimulate the enthusiasm of employees as well as to continuously improve their work literacy and ability. Therefore, the reform of human resource management in hospitals still needs to use this as an entry point. At present, most medical companies are beginning to realize the positive impact of incentives on employees where they use incentive methods to stimulate their internal driving force and professionalism in order to achieve the goal of improving work quality and efficiency. It can be appreciated that it is extremely necessary to examine and analyze the specific application of incentive theory in hospitals' human resource management.

\section{Overview of incentive theory}

Incentive is mainly to stimulate the initiative and enthusiasm of individuals or groups through actions, materials, and words. The reason for the establishment of incentives is that the demand has not been met whereas the end criterion of an incentive is whether the demand has been met or the incentive is invalid ${ }^{[1]}$. Incentives also need to change because people's needs are endless. Especially in daily lives, people have formed a certain understanding of the important role of incentives. Hence, the theoretical research on incentives is also more in-depth. In this way, a system concept is formed, and it is widely used in management. The incentive theory in management can be refined into two parts:

(1) From the perspective of psychology, the results of the research generally include Maslow's hierarchical of needs, Murray's theory of needs, Herzberg's two-factor theory, etc. 
(2) From the perspective of behavioral analysis, the results of the research include labor expectancy theory, Adam's equity theory, and so on.

In order to continuously improve the efficiency of the human resource management in hospitals and ensure that the quality of treatment services meets the standards, it is necessary to effectively integrate the incentive theory in hospitals' human resource management to enhance the cohesion between employees as well as to stimulate their initiative and creativity to well achieve organizational goals.

\section{Significance of incentive mechanism in hospitals' human resource management}

The role of the incentive mechanism in hospital management should not be underestimated. It is not only conducive to the professional development of employees, but also conducive to the sustainable development of a hospital ${ }^{[2]}$. Analyzing from the perspective of employees, the use of incentives can cultivate their professional well-being as well as make them more active and proactive at work. With the improvement of the levels of staffs, the competitiveness and cohesion in hospitals will inevitably be strengthened.

First of all, the work enthusiasm of the staffs is mobilized. A doctor's mission is to save the dying and heal the wounded. Their work is extremely difficult which is characterized by long hours and high intensity; hence, putting forward higher requirements on their physical strength and ability. For this reason, it is necessary to rationally choose material incentives and spiritually fierce methods in the development of human resource management so that they would be able to truly experience personal values.

Second, the core competitiveness of hospitals has been significantly enhanced. The use of incentive mechanism can significantly enhance employees' professional happiness and self-worth. In this way, they would then invest more energy in their work which would enhance the effectiveness of human resource management. In work practice, it is necessary to follow the principles of humanistic care. Various activities should be organized between employees such as dinners and outings so that their hearts would be closer, and the exchange of their thoughts can be better carried out in order to create tacit cooperation for future work and ultimately achieve the goal of improving professional skills. In this way, hospitals can achieve different levels of development and enabling the masses to obtain better quality medical services.

Finally, the cohesion in hospitals is enhanced. The main purpose of hospitals' human resource management is to standardize the work behavior of employees and obtain ideal performance by improving service quality. Reasonable choices of incentive methods should be made to create a more harmonious working environment for employees, enhance their sense of professional belonging, demonstrate the charm of modern management, and give play to the role of humanistic care. At this point, hospital staffs can then recognize the importance of the hospitals' development for themselves ${ }^{[3]}$.

\section{Application of incentive theory in hospitals' human resource management}

Based on the above content regarding incentive theory, it is more conducive to the sustainable development of the hospital to integrate this theory into hospitals' human resource management.

\subsection{Material incentives}

Material incentives are very common in human resource management. Their effects are relatively obvious and widely used. For hospitals' internal staffs, no matter what job they are engaged in, they need to take material as an important guarantee. Only when their material needs are met, their other needs would be displayed. For this reason, material incentives play a key role in the process of hospitals' human resource management ${ }^{[4]}$. It is necessary to scientifically select material incentive methods in order to achieve the purpose of mobilizing the enthusiasm and initiative of employees so that hospitals are able to achieve more 
considerable benefits. In applying material incentives, the fairness and justice of the incentive methods must be ensured. In general, incentive funds can be increased in regard to the basic salary. For public hospitals, the salary management method of national institutions is generally selected, and the internal control is limited. Therefore, incentive policies should be implemented based on salary assessment.

\subsection{Spiritual incentives}

In terms of spiritual incentives, specific methods and measures should be reasonably selected to effectively stimulate the inner psychological activities of employees so as to achieve the purpose of being motivated and have higher work enthusiasm. Under normal circumstances, the most commonly used method of spiritual incentive is to recognize the employees' work performance or to upgrade their honor levels, position levels, etc. Compared with material incentives, the meticulous characteristics of spiritual incentives are more obvious in addition to more complicated and cumbersome work content, but the actual incentive effect has a more profound impact on employees ${ }^{[5]}$. Through the use of spiritual incentives, the employees' loyalty, trust, and sense of belonging to their hospitals can be enhanced. Generally speaking, the methods of spiritual incentive mainly include the following aspects:

First, care and support should be provided to the internal staffs in terms of work and life. The same should be provided to individual staffs and workers as much as possible to adapt to the spiritual needs of the staffs. The reasonable use of spiritual incentives can better condense the emotions of employees which then achieves the purpose of retaining talents.

Second, hospitals' internal leaders should summarize the strengths and work performance of the staffs, praise them more, and at the same time, inform them about the main focus of their work for them to pay attention to in order to prevent mistakes that adversely affect their work enthusiasm.

Third, the internal leaders should also have a thorough understanding of their staffs' abilities and attitudes in taking reasonable measures to help them.

Fourth, for employees with strong working ability, the hospital should reasonably adopt reward and encouragement methods, which can be done by awarding honorary titles ${ }^{[6]}$.

\subsection{Environmental incentives}

People's lives and work styles are easily affected by environmental factors, but they are often overlooked. The hospital is a special place where if one ignores the influence of environmental factors, it is easy for adverse consequences to occur. Hence, it is necessary to emphasize on the role of environment in the implementation of human resource management work in hospitals to actively create a warmer and more harmonious working environment. First of all, hospitals should continuously improve the construction of infrastructures such as internal medical building facilities and equipment in addition to timely supplement and update their internal medical facilities. Only in this way the integrity of the hospitals' hardware facilities can be guaranteed, and the market competitiveness can be continuously enhanced. Secondly, there is a need to comprehensively build the cultural environment in hospitals by regularly organizing and carrying out cultural exchange activities or entertainment activities, paying attention to the role of communication between employees, as well as forming more harmonious working and interpersonal relationships so that the problems existing between employees and departments can be solved and eventually, further optimizing the quality and efficiency of interdepartmental cooperation. Finally, hospitals need to pay attention to the ward environment from the internal layout to the living facilities; all of them need to meet human needs so that patients can receive treatment in a warmer environment for speedy recovery. 


\subsection{Institutional incentives}

Institutional incentives are expressed in the form of personnel distribution system in hospitals' human resource management center. With the help of institutional incentives, hospitals would acquire a double benefit. On the one hand, the intensity of innovation should be raised, and human resource management mechanisms should be reformed by systematically developing the human resources and effectively integrating the needs of human resource construction management and the hospital development ${ }^{[7]}$. On the other hand, the investment in hospitals' human resources development and management should be increased to ensure that human resources are in a virtuous circle. Through reasonable selection of medical technology, high-quality medical personnel are allocated to achieve the purpose of retaining professional personnel.

\subsection{Job title incentives}

In the modern medical and health system, job title incentives are also very common and play an important role in human resource management. Reasonable use of job title incentives can enable employees to better improve themselves and give full play to their value in the medical field. It should be noted that the technical characteristics of hospital work are obvious, and there is a large demand for professional and technical personnel. If these personnel work hard enough, they would be able to have the opportunity to play certain roles. Therefore, it is necessary to learn professional business knowledge in order to improve their comprehensive quality and achieve the purpose of improving their job titles. On the other hand, hospitals should establish a sound promotion mechanism for professional titles and provide assistance for employees' self-improvement and progress. On the basis of creating job title incentives, it is also necessary to emphasize the role of lifelong mechanism of violations to ensure that the directors of various departments in hospitals follow the principle of "survival of the fittest" and implement competitive methods to enable employees to give full play to their values.

\subsection{Further education incentives}

Based on the development of economic globalization, the world is always in a state of change, and medical knowledge is also constantly renewing and changing. Under this circumstance, medical staffs also need to keep pace with the times and actively learn to absorb new medical knowledge. In particular, hospital workers with high qualifications and even if they have rich practical experiences, they are still inadequate in the context of rapidly updating their medical knowledge. For this reason, most of the hospitals' internal staffs prefer to improve their personal professional knowledge and practical skills ${ }^{[8]}$. The development of internal human resource management in hospitals must also emphasize the role of further education incentives and provide employees with these opportunities as much as possible so as to enrich their own experience, improve their knowledge and technical level, as well as enable hospitals to achieve more considerable social and economic benefits.

\section{Conclusion}

In summary, the sustainable development of hospitals has a high demand for human resources. Once human resources are insufficient, it would inevitably affect the survival of the hospitals. Especially with fierce market competition, hospitals need to emphasize the importance of human resource management, rationally adopt management methods, comprehensively build human resource management mechanisms, and through the effective integration of incentive theory, human resources would achieve a virtuous circle, and ultimately realize the healthy development in hospitals. 


\section{Disclosure statement}

The author declares that there is no conflict of interest.

\section{References}

[1] Wang J, 2021, The Construction of Modern Hospital Human Resource Management Incentive Mechanism from the Perspective of Demand Hierarchy Theory. Business Intelligence, (1): 173-4.

[2] Li YL, 2021, Exploring the Construction of Modern Hospital Human Resource Management Incentive Mechanism from the Perspective of Demand Hierarchy Theory. China Science and Technology Investment, (1): 189-90.

[3] Wu J, 2021, Thoughts on the Construction of Modern Hospital Human Resource Management Incentive Mechanism based on the Hierarchy of Needs Theory. Business Economics, (5): 93-4, 102.

[4] Ma DN, Ye STY, Wang YY, 2017, The Integration and Penetration of Motivation Theory in Hospital Human Resource Management. China Health \& Nutrition, 27(25): 383.

[5] Gao L, 2018, The Application of Two-Factor Motivation Theory in the Human Resource Management of Public Hospitals. China Health Care and Nutrition, 28(26): 396-97.

[6] Lu YR, 2020, Analysis of Hospital Human Resource Management based on Hierarchy of Needs and Two-Factor Theory. Chinese Health Standard Management, 11(22): 20-2.

[7] Liu Y, Xue MX, Li HB, et al., 2014, Human Resource Management in Public Hospitals based on Snell Model and Two-Factor Incentive Theory. Chinese Health Quality Management, 21(3): 85-7.

[8] Yu QM, Chen Z, Li BQ, et al., 2019, The Construction of Modern Hospital Human Resource Management Incentive Mechanism from the Perspective of Demand Hierarchy Theory. Chinese Journal of Social Medicine, 36(4): 352-4. 